\title{
Towards a Systematic Exploitation of Web 2.0 and Simulation Modeling Tools in Public Policy Process
}

\author{
Yannis Charalabidis $^{1}$, George Gionis ${ }^{2}$, Enrico Ferro ${ }^{3}$, and Euripidis Loukis ${ }^{1}$ \\ ${ }^{1}$ University of the Aegean, Gorgyras Str., Karlovassi 83200, Greece \\ \{yannisx, eloukis\} @ aegean.gr \\ ${ }^{2}$ National Technical University of Athens, 9 Iroon Polytechniou, Athens 15780, Greece \\ gionis@epu.ntua.gr \\ ${ }^{3}$ Istituto Superiore Mario Boella, 61Via Boggio, Turin 10138, Italy \\ ferro@ismb.it
}

\begin{abstract}
This paper describes a methodology for the systematic exploitation of the emerging web 2.0 social media by government organizations in the processes of public policies formulation, aiming to enhance e-participation, in combination with established simulation modeling techniques and tools. It is based on the concept of 'Policy Gadget' (Padget), which is a micro web application combining a policy message with underlying group knowledge in social media (in the form of content and user activities) and interacting with citizens in popular web 2.0 locations in order to get and convey their input to policy makers. Such 'Padgets' are created by a central platform-toolset and then deployed in many different Web 2.0 media. Citizens input from them will be used in various simulation modeling techniques and tools (such as the 'Systems Dynamics'), which are going to simulate different policy options and estimate their outcomes and effectiveness. A use case scenario of the proposed methodology is presented, which outlines how it can be used in 'real life' public policy design problems.
\end{abstract}

Keywords: e-participation, web 2.0, social media, public policy, simulation, system dynamics.

\section{Introduction}

The design of public policy in most domains is a 'wicked' problem, since it is characterised by high complexity and many stakeholders with different and heterogeneous views of the problem, values, concerns and interests; such problems do not have mathematically 'optimal' solutions and pre-defined algorithms for calculating them, but only 'better' and 'worse' solutions, so they cannot be solved by formal methodologies and require 'second generation' approaches based on deliberation among stakeholders [1] - [4]. These approaches include several circles of deliberation, in which the stakeholders interact, raise issues concerning the problem under discussion, propose solutions and argue about advantages and disadvantages of them, finally resulting in a better understanding of the problem. From a knowledge management perspective in such deliberations valuable 'tacit knowledge' possessed 
by the stakeholders is transformed into 'explicit (codified) knowledge' [5] - [6], which can be processed, disseminated and combined with other relevant knowledge that public organizations possess, in order to formulate better policies and regulations for addressing social needs and problems and deliver better services to citizens and enterprises.

For these reasons a new model of democracy has emerged, which is termed "participatory democracy" [7] - [11], and combines decision making by citizens' elected representatives with citizens' participation, with the latter not replacing but supporting and enhancing the former. A key principle of this model is that "the equal right to self-development can only be achieved in a participatory society, a society which fosters a sense of political efficacy, nurtures a concern for collective problems and contributes to the formation of a knowledgeable citizenry capable of taking a sustained interest in the governing process" (Held 1987, [9], p. 262). Row and Frewer (2004) [11] define public participation as "the practice of consulting and involving members of the public in the agenda-setting, decision-making and policy forming activities of organizations or institutions responsible for policy development'. The development and increasing penetration of information and communication technologies (ICT), and Internet in particular, in many countries enables the extensive application of the above principles through electronic media, which has been termed as e-participation [12] - [15]. According to the OECD [12], [13] e-participation is defined as the use of ICTs for supporting the provision of information to the citizens concerning government activities and public policies, the consultation with the citizens and also their active participation.

However, despite the high public investments that have been made in many countries by government organizations for developing 'official' e-participation websites aiming to inform citizens on various public policies under formulation and have various types of interactions and consultations with them, their use by the citizens has been in general limited and below the initial expectations [16]; most of these official e-participation spaces were largely unknown to the general public due to the high costs of promotion and the slow pace of dissemination, while the topics dealt with were sometimes distant from people's daily problems and priorities, so that content contributions by non experts was inhibited. These problems, in combination with the high heterogeneity of citizens in terms of political interests, educational level and technological skills, and at the same time the emergence of the new Web 2.0 social media necessitate government to exploit the numerous users-driven Web 2.0 virtual spaces, which have been launched through citizens initiatives with dramatic success in terms of adoption and usage, for widening and enhancing e-participation. Web 2.0 initially had a big impact on the social life of people, and later on several private sector industries, such as advertising and media; however, recently there has been some first evidence that Web 2.0 applications are relevant for supporting various tasks in many different domains of government, including public participation [17].

In this direction this paper describes a methodology for the systematic exploitation of the emerging Web 2.0 social media, in combination with the 'established' simulation modelling techniques and tools, by central and local government organizations in the processes of public policies formulation. Though in recent literature are presented some guidelines and frameworks for the exploitation of Web 2.0 by private sector firms [18], [19], something similar for the public sector is 
missing. In particular, the proposed methodology aims at bringing together two well established domains, the mashup architectural approach of Web 2.0 for creating web applications (termed as Policy Gadgets - Padgets) and the simulation modelling techniques and tools for analyzing complex system behaviour, such as System Dynamics [20].

The paper is structured in seven sections. In section 2 the background and foundations of the proposed methodology is outlined, which includes results from previous research on the use of web 2.0 in government and simulation modelling. Then in section 3 the fundamentals of our methodology are presented, while in section 4 the architecture of the central platform for creating and deploying Padgets is described. Section 5 presents an application scenario of the proposed methodology, which outlines how it can be used in 'real life' public policy design problems. Finally, section 6 summarizes the conclusions and the next steps we are going to take for validating the proposed methodology.

\section{Background}

\subsection{Web 2.0 and Government}

Web 2.0 is defined as a set of technologies, applications and values [17], [21]. In particular, from the technological point of view, the building blocks of Web 2.0 are a number of new technologies, such as Ajax, XML, Open API, Microformats, Flash/Flex, which have been developed and introduced aiming to increase the usability, integration and re-use of web applications. Based on these technologies some applications have been developed, which enable easy content creation and publishing, information sharing and collaboration, such as Blog, Wiki, Podcast, RSS feeds, Social networks, Massive Multiplayer Online Games, etc. These applications share some common values. They build on the knowledge and skills of the user, and enable the user to build content and services (termed as the 'user as producer' value), reducing the content and services producer and consumer dichotomy. User contributions can be made more meaningful and rich through collaboration and networking among users, while the quality control filtering relies strongly on peer review by other users (termed as the 'collective intelligence' value). Also, applications are first released in beta format in order to include early user feedback, and very often are continuously improved (this termed as the 'perpetual beta' value), rather than following a linear development process. Finally in Web 2.0 usability is highly important, because the success of these applications rely critically on the quantity and quality of users' contributions, so their take-up is not only an index of success, but often a condition for their continued existence (this termed as the 'extreme ease of use' value).

Web 2.0 was initially used by people for personal and social communication, while later it was used by several private sector industries, such as advertising and media, and had an important impact on them. In recent literature are presented some guidelines and frameworks for the exploitation of Web 2.0 by private sector firms for marketing purposes [18], [19]. Recently, there has been some first evidence [17] that Web 2.0 applications are already being used in government, not only for 'soft' issues, such as public relations and public service announcements, but also for 'core' tasks, such as 
intelligence services, reviewing patents, knowledge management, cross-agency collaboration, public services evaluation by citizens, regulation, law enforcement and public participation. These applications of Web 2.0 in government aim to and result in a more active 'user' role, having as users both civil servants and citizens. However, a comprehensive methodology and toolset for exploiting systematically web 2.0 social media by government organizations is missing.

Focusing now on the area of public participation, previous research [16] has found that numerous e-participation experiments has been documented in Europe and abroad, which have used different technologies and various methodologies to purport to highly heterogeneous policy goals, however their usage by the citizens has been in general limited, much lower than expectations, and some important weaknesses have been identified:

- public administrations expected citizens to make the first step: to move forward from their own online environments to government websites for participating in public debates;

- the designated "official" spaces were largely unknown to the general public, mainly due to the high costs of promotion and the slow pace of dissemination;

- the topics discussed were sometimes distant from people's daily problems and priorities, so that content contributions by non experts was inhibited;

- the tools adopted were not appropriate, or at least usable only by a rather reach and educated minority;

- the methodologies used for e-participation were not scalable, so they could only be adopted in pilot trials with a limited impact;

- and also the distribution of online users behavior was not taken into account (only a small minority of Internet users is willing to actively produce content or offer reviews/feedbacks).

For the above reasons it is concluded that a change of approach in the implementation of e-participation by government is necessary, taking into account and exploiting the development and high penetration of Web 2.0 and mobile communications. In particular, the increased capabilities for Internet users to create content and the birth of social networks have driven the development of more and more virtual spaces for the expression of political views, problems and needs. At the same time the pervasive diffusion of mobile Internet in most citizens' groups (even in less rich and educated ones, who make limited use of Internet) deserves a more careful consideration from eparticipation designers. Therefore governments should become more aware of the social complexity, and at the same time the wealth of information that is already available and is continuously developed in citizens-initiated Web 2.0 social media, in order to increase the quantity, quality and inclusiveness of e-participation; they should make a step towards citizens rather than expecting the citizenry to move their content production activity onto the "official" spaces created for e-participation.

\subsection{Simulation Modelling}

Modeling has been used for long time as a way of understanding complex social and technical systems, estimating their evolution/performance and addressing their 
problems that, especially when prototyping or experimenting with the real system is too costly or impossible [22]. We can distinguish between analytical and simulation modeling. Simulation modeling is a good approach for complex systems and problems, in which time dynamics is important and an analytical solution is difficult. A simulation model may be considered as a set of rules (expressed in various forms, such as equations, flowcharts, state machines, cellular automata) that define how the system behaves and evolves with time. There are four basic paradigms of simulation modeling, which differ mainly in the level of abstraction and detail and also in the way they model time (using continuous or discrete time):

- Dynamic Systems: It is actually the ancestor of System Dynamics, which is used for the detailed modeling (at a low abstraction level) in continuous time of mechanical, electrical, chemical, and other technical systems, as part of their design process.

- System Dynamics: It has been initially developed for analyzing from a high level of abstraction in continuous time the information-feedback characteristics of industrial activities and examine how various types of amplification, time delays and organizational structures affect performance. However, latter it has been extensively used for modeling and analyzing many other types of systems, such as urban, social, ecological, etc. System Dynamics models a real-life activity as a set of 'stocks' (of quantities gradually accumulated, e.g. people, money, material, etc.), 'flows' between these stocks and also 'information' that determines the levels of these flows.

- Discrete Events Modeling: It is used for modeling at a medium or low level of abstraction systems which are characterized by discrete events that determine their evolution and performance.

- Agent Based Modeling: It is based on modeling the behavior of the individual 'agents' forming the systems, which are defined as objects characterized by pro- and re-activeness, spatial awareness, ability to learn, social ability and "intellect". Therefore the behavior at the system level is not defined, but emerges as a result of many individual agents, each following its own behavior rules, living together in some environment and communicating with each other and with the environment.

From these four basic paradigms of simulation modeling Systems Dynamics (being described in detail in [20], [23], [24]) seems more appropriate for analyzing public policies, since this usually i) requires high level views of complex social or economic systems in continuous time, and ii) such systems include various individual processes with 'stocks' (e.g. users and non-users of various services or new technologies, employed and unemployed citizens, citizen groups of various income levels, etc.) and 'flows' among them, which are influenced by public policies. For this reason Systems Dynamics has been successfully used in the past for estimating the evolution of a number of critical variables for society, such as unemployment, economic development, taxation income, technologies penetration, pollution, poverty, etc. and for the analysis of various types of public policies, e.g. [25] - [30]. Systems dynamics focuses on understanding initially the basic structure of a system and then based on it understanding the behavior it can produce (e.g. exponential growth or S-shared growth of the basic variable). 


\section{Methodology Fundamentals}

The proposed methodology in based on the background and foundations presented in the previous section, and brings together two well established domains: the mashup architectural approach of web 2.0 for creating web applications (gadgets) and the methodology of simulation modelling for analyzing complex systems behaviour. Its main objective is to design, develop and deploy a prototype central toolset that will allow policy makers to create graphically micro-applications, which are then going to be deployed in many different web 2.0 social media (each of them can have a different audience, so that we can finally reach appropriate groups of citizens, which are quite different from the ones who visit and use the official government-initiated eparticipation websites) in order to convey policy messages to their users and interact with them. Similarly to the approach of gadget applications in web 2.0 - i.e. using data and services from heterogeneous sources to create and deploy quickly applications that provide value added services - the project introduces the concept of 'Padget' (Policy Gadget) to represent a micro web application that combines a policy message with underlying group knowledge in social media (in the form of content and user activities) and interacts with end users in popular web locations (such as social networks, blogs, forums, news sites, etc) in order to get and convey their input to policy makers.

In particular, as we can see in Figure 1 a Padget is composed of four elements:

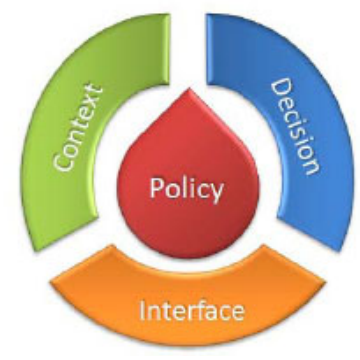

Fig. 1. The elements of a Padget

- A policy message, which could be a public policy in any stage, e.g. a policy white paper, a draft policy plan, a legal document under formulation, a law in its final stage, an EU directive under implementation, etc.

- An interface that will allow users to interact with the policy gadget; this interface will be relevant to the Padget objective - for example it may give users the capability to access policy documents, be informed on relevant news, stipulate opinions, vote on some issues, upload material, tag other people opinions or content as relevant, get location based information, etc.

- Relevant group knowledge, in the form of relevant content and users' activities that have been produced in external social media, forums, blogs, wikis, social networks, etc., which concerns the above policy, is properly annotated in order to indicate its relation with a particular web 2.0 location and constitutes the context of the Padget. 
- A decision support model, which includes simulation modelling methods and tools (such as Systems Dynamics), using as input the above data from the interaction of the Padget with the public, and giving as output the effect of specific policies on critical performance indicators that are of interest to the policy maker.

Additionally, any Padget will include a privacy statement informing the citizen as a potential user about what kind of personal data will be collected, how it will be used and processed, and what will happen to it after the expiration of the Padget.

Such a Padget can be deployed in many different web 2.0 social media. In particular, we are going to target the following categories of media (and from each category choose the most appropriate ones taking into account the particular public policy under discussion and the audience we would like to involve in the discussion):

- Platforms for Communication, such as Blogs, Internet forums, Presence applications, Social networking sites, Social network aggregation sites and event sites.

- Platforms for Collaboration, such as Wikis, Social bookmarking (or Social tagging) sites, social news and Opinion sites.

- Platforms for Multimedia and Entertainment, Photo sharing, Video sharing, Livecasting and Virtual World sites.

- Platforms for News and Information, such as Goggle News, Institutional Sites with high number of visitors (i.e. EU, Human Rights and WWF sites) and newspaper sites.

- Platforms for Policy Making and Public Participation, such as governmental organisations forums, blogs, petitions, etc.

Each of them usually provides open APIs in the form of Web services for communicating with it; these programming interfaces are characterized by their simplicity and are often based on existing standards such as HTTP, URL/URI, XML, etc. The application field of Web services is very extensive, but in the context of Web 2.0 are mainly used REST web services. The reason for this is that in web2.0 the Internet is viewed as a collection of resources, which can be easily retrieved or manipulated with REST-based interfaces.

With respect to the decision model, it should be mentioned that it will receive as input the alternative policy scenarios and actions that have been planned by decision makers in combination with existing data referring to the policy issue (studies, statistical data, background information) and also data gathered by Padgets' interaction with end users (opinion polls, survey results etc.) e.g. referring to the adoption rate of the planned policy actions among citizens and other stakeholders. Based on the operation of a simulation engine, embedded in the Padget decision model the potential policy outcomes will be estimated in a hypothetical basis of applying them over a specific time period. These outcomes, after aggregation with existing background information about the particular policy issue, will be used as input for simulating policy actions related to the next steps of the policy making process; this procedure is going to be repeated several times (according to the alternative policy scenarios duration and the policy making process stages), creating thus several loops, in order to end up to the final outcomes and impact of each policy scenario and finally give the decision makers a basis for making the best possible decision. This will also enable the development of hybrid scenarios and policies if needed, in order to manage the particular social problem or need in a better way. 


\section{Central Platform Architecture}

The central platform will provide capabilities for creating graphically Padgets and deploying them in many different Web 2.0 media. Its architecture is shown in Figure 2. It consists of several modules, which are partly dependent on each other and easily expandable. These modules can be divided into two categories: the first one includes internal and 'non-visible' modules, such as the composition module, while the second category includes 'visible' modules responsible for the interaction with the Padgets designers and administrators, such as the Web module and REST-module.

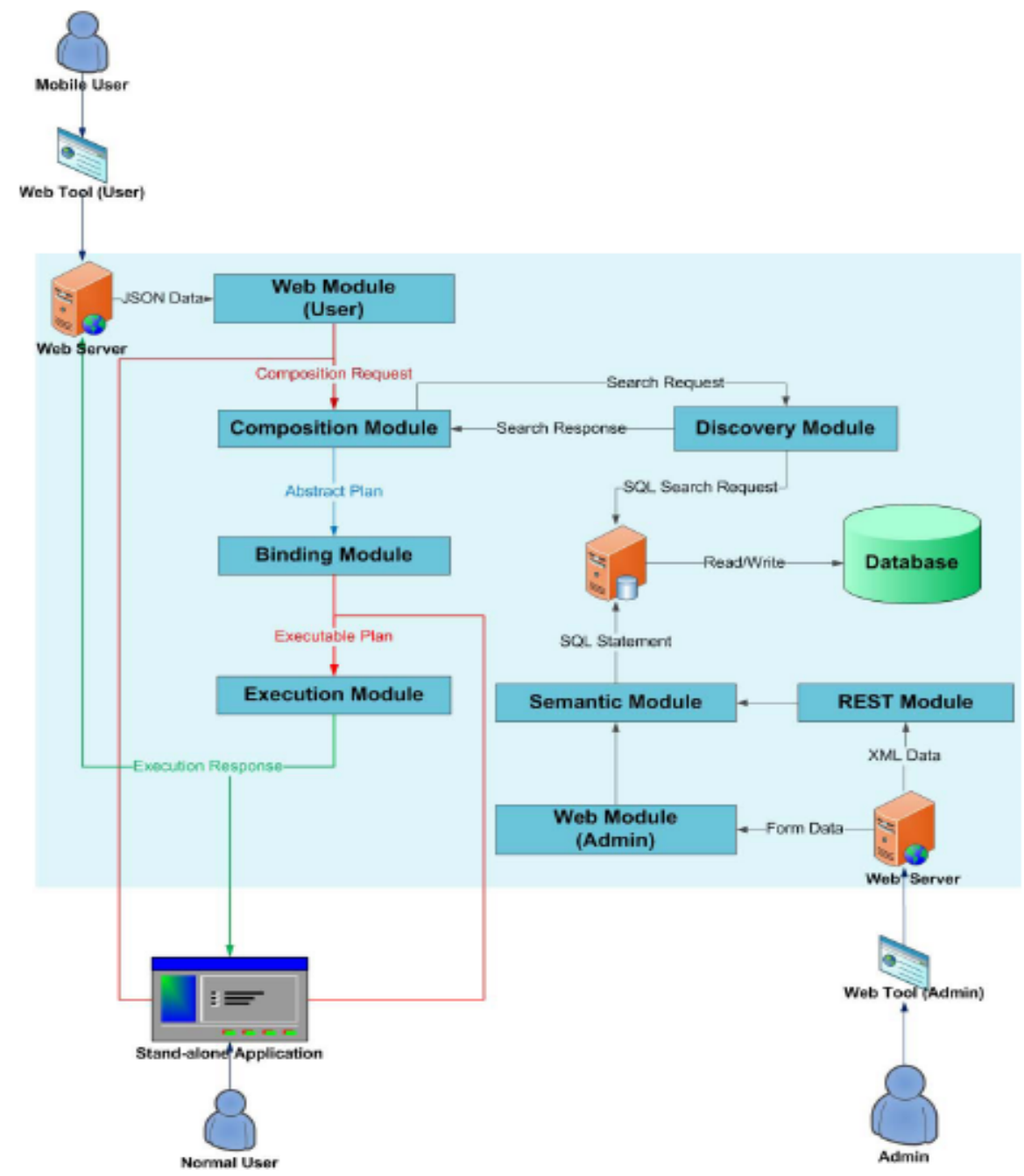

Fig. 2. Architecture of the central platform 
In particular the main modules of the central platform are:

Semantic Module: In this module the new language for semantic service description will be implemented; all semantic information will be stored in a database, so this module provides an interface for managing the semantic information in the database.

Discovery Module: The main task of this module is to find all services, which fit to a request; thereby different search strategies can be implemented.

Composition Module: This module is implementing a scheduling algorithm for automatic service composition; it tries to create all plans for a request (request composition), which are leading to a goal. In order to complete its task, this module communicates constantly with the discovery engine and sends in each composition step a search query.

Binding Module: This module converts abstract plans into executable plans; for this purpose it searches and integrates specific services.

Execution Module: It receives as input the plans from the previous module and executes them.

Web Module: This module provides a web interface to communicate with the system. On the client side the user can create a Padget graphically via a Web-Tool, which will be transformed in a suitable format and send to the server. On the server side the Web module receives the request and forwards it to the Composition-module. Then comes the binding module, and at the end the execution module. The Padget is shown on the client side.

REST Module: This module provides a RESTfull interface, which can communicate to the Semantic module.

Standalone Application: Is an installable application with a graphical interface to create and deploy Padgets in blogs, wikis and communities.

\section{An Application Scenario}

A simple and typical application scenario of the proposed methodology in the policy making processes, based on the use of the above central platform, would start from a policy maker or policy making group wanting to "harvest society's input" in order to take decisions about a future policy to be introduced, or to evaluate whether an already implemented policy aligns with the society or needs modifications. The steps to be taken are shown in Figure 3:

I) The policy maker uses the platform capabilities to Design an appropriate Padget through a graphical drag-and-drop user interface, similar to the one of existing mashup editors for creating gadget applications.

II) The Padget is then Published via the platform to a number of appropriate (in terms of the audience we want to consult for the particular public policy) Web 2.0 social media and becomes available to the public. There will be a variety of choices for deploying the Padget through the central platform according to the its objective and targeted audience. For example it can be deployed to a social network in the form of a specific policy application, as an embedded petition, poll or social tagging application in the sidebar of a popular blog, wiki or forum, or even in the platform's own registry. 


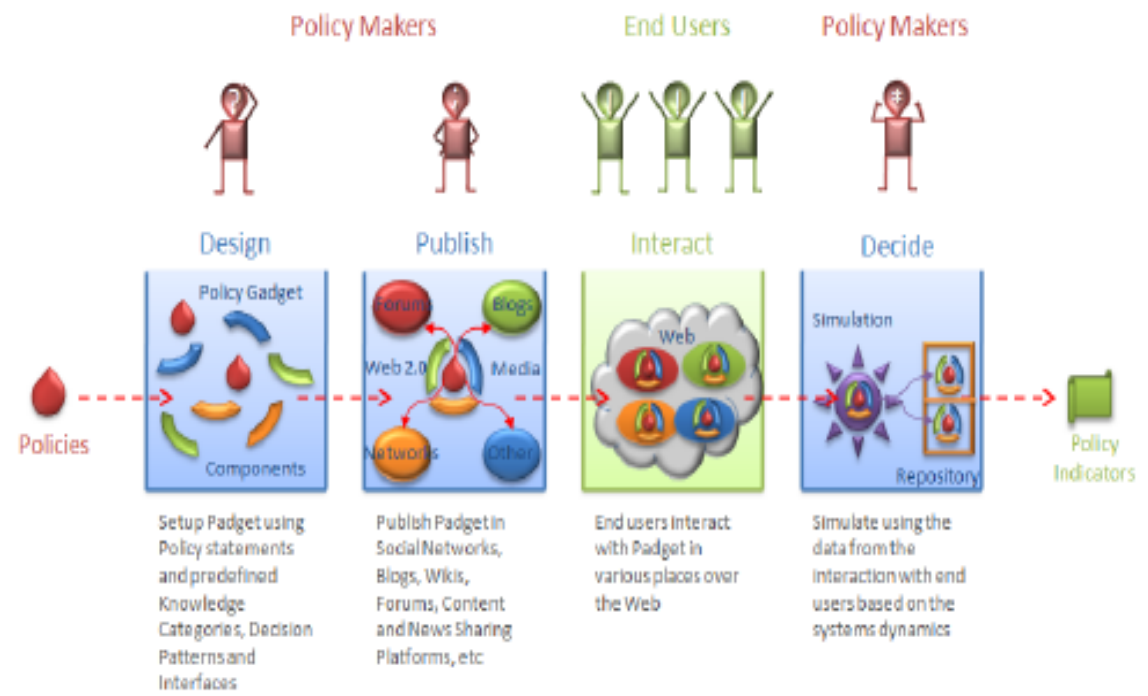

Fig. 3. Steps of a typical application of the proposed methodology

III) The Padget Interacts with the public in all these web locations. This means that users can access it, see its policy message, access the related content and using the Padget's interface interact with it, i.e. relate stipulate opinions, add material, vote and even create relations to other existing similar Padgets. The above will be performed in a privacy preserving manner in accordance with the privacy preferences of users.

IV) At the last stage the Padget helps the policy maker to Decide and form a better understanding of the public policy at stake. For this purpose simulation modelling techniques and tools will be used, such as System Dynamics, which will use as input the data from the interaction of the Padget with the public and simulate how the specific policy (or even a number of alternative policies) will affect a number of critical performance/effectiveness indicators.

\section{Conclusions}

In the previous sections, a methodology has been described that allows the systematic and centralised exploitation of the 'emerging' Web 2.0 social media, in combination with the 'traditional' simulation modelling techniques and tools, in order to support participatory policy making activities. The proposed methodology allows for a broader, deeper and more inclusive citizens' e-participation in the formulation of significant public policies, by taking advantage of the emerging and highly used web 2.0 social media and involving various different groups who do not usually visit the official e-participation stages of government organizations. This novel e-participation approach enables the government to make a step towards citizens, going to the web locations each group is using for interaction, rather than expecting the citizens to move their content production activity onto the "official" spaces created for eparticipation. In this way more valuable 'tacit knowledge' on important social 
problems and needs, and policy options for addressing them, which is possessed by various stakeholders can be transformed into 'explicit (codified) knowledge'.

This methodology will be further validated in the PADGETS project (its full title being 'Policy Gadgets Mashing Underlying Group Knowledge in Web 2.0 Media www.padgets.eu) supported by the Seventh Framework Programme (ICT for Governance and Policy Modelling research initiative) of the European Commission. For this purpose initially an analysis will be made of the domain of Web 2.0 social media for news sharing, social networking, publishing and broadcasting, communication and collaboration, followed by identification of standards, interfaces and APIs that allow for interacting with these platforms and tools. Based on the conclusions of these analyses the detailed design will be finalised of the central platform for creating and deploying Policy Gadgets as well as of the ways of exploiting Padgets for providing decision support to policy makers and enabling a more socially-rooted, citizen-centric policy making. Finally the proposed methodology and the above technological tools will be validated through a number of pilots in real life conditions, so that their added value in the policy making process can be assessed and possible improvements of them.

\section{References}

1. Rittel, H.W.J., Weber, M.M.: Dilemmas in a general theory of planning. Policy Sciences 4, 155-169 (1973)

2. Buckingham Shum, S.: The Roots to Computer Supported Collaborative Argument Visualization. In: Kirschner, P.A., Buckingham Shum, S., Carr, C.S. (eds.) Visualizing Argumentation: Software Tools for Collaborative and Educational Sense-Making, pp. 3-20. Springer, London (2003)

3. Girle, R., Hitchcock, D., McBurney, P., Verheij, B.: Decision Support for Practical Reasoning: A Theoretical and Computational Perspectiv. In: Reed, C., Norman, T.J. (eds.) Argumentation Machines: New Frontiers in Argument and Computation, pp. 55-83. Kluwer Academic Publishers, Dordrecht (2003)

4. Karacapilidis, N., Loukis, E., Dimopoulos, S.: Computer-supported G2G collaboration for public policy and decision making. Journal of Enterprise Information Management 18(5), 602-624 (2005)

5. Nonaka, I.: A Dynamic Theory of Organizational Knowledge Creation. Organization Science 5(1), 14-37 (1994)

6. Cohendet, P., Steinmueller, W.E.: The Codification of Knowledge: a Conceptual and Empirical Exploration. Industrial and Corporate Change 9(2), 195-209 (2000)

7. Pateman, C.: Participation and Democratic Theory. University Press, Cambridge (1970)

8. Barber, B.: Strong Democracy. University of California Press, Berkeley (1984)

9. Held, D.: Models of Participation. Polity Press, Cambridge (1987)

10. Rowe, G., Frewer, L.J.: Public Participation Methods: A Framework for Evaluation. Science, Technology \& Human Values 25(1), 3-29 (2000)

11. Rowe, G., Frewer, L.J.: Evaluating Public-Participation Exercises: A Research Agenda. Science, Technology, \& Human Values 29(4), 512-557 (2004)

12. Organization for Economic Co-operation \& Development (OECD): Engaging Citizens Online for Better Policy-making. Policy Brief, Paris (2003)

13. Organization for Economic Co-operation \& Development (OECD): Promise and Problems of e-Democracy: Challenges of Online Citizen Engagement. Paris (2004) 
14. Macintosh, A.: Characterizing E-Participation in Policy Making. In: Proceedings of the 37th Hawaii International Conference on System Sciences (2004)

15. Timmers, P.: Agenda for eDemocracy - an EU perspective. European Commission (2007)

16. Ferro, E., Molinari, F.: Making Sense of Gov 2.0 Strategies: No Citizens, No Party. In: Prosser, A., Parycek, P. (eds.) Proceedings of EDEM 2009 (2009)

17. Osimo, D.: Web 2.0 in Government: Why and How? JRC Scientific and Technical Reports. European Commission, Joint Research Centre, Institute for Prospective Technological Studies (2008), http: / / ftp.jrc.es/EURdoc/JRC45269.pdf (retrieved)

18. Constantinides, E.: Social Media/Web 2.0 as Marketing Parameter: An Introduction. In: Proceedings of 8th International Congress Marketing Trends (2009)

19. Constantinides, E.: Connecting Small and Medium Enterprises to the New Consumer: The Web 2.0 as Marketing Tool. In: Global Perspectives on Small and Medium Enterprise. IGI Global, Hershey (2010)

20. Kirkwood, C.W.: System Dynamics Methods - A Quick Introduction. Arizona State University,

http://www.public.asu.edu/ kirkwood/sysdyn/SDWork/work-f.pdf (retrieved)

21. O' Reilly, T.E.: What is web 2.0 (2005),

http: / /www . oreillynet.com/pub/a/oreilly/tim/news/2005/09/30/

what-is-web-20.html (retrieved)

22. Borshchev, A., Filippov, A.: From System Dynamics and Discrete Event to Practical Agent Based Modelling: Reasons, Techniques, Tools. In: Proceeding of 22nd International Conference of the System Dynamics Society, Oxford, England (2004)

23. Forrester, J.: Industrial Dynamics: A Major Breakthrough for Decision Makers. Harvard Business Review 36(4), 37-66 (1958)

24. Forrester, J.: Industrial Dynamics. MIT Press, Cambridge (1961)

25. Liu, C.Y., Wang, W.T.: System Dynamics Approach to Simulation of Tax Policy for Traditional and Internet Phone Services. In: Proceedings of the 23rd International Conference of the System Dynamics Society, Boston (2005)

26. Homer, J.B., Hirsch, G.B.: System Dynamics Modelling for Public Health: Background and Opportunities. American Journal of Public Health 96(3), 452-458 (2006)

27. Robert, Y.C., Leslie, V.C.: Demonstrating the utility of system dynamics for public policy analysis in New Zealand: the case of excise tax policy on tobacco. System Dynamics Review 22(4), 321-348 (2006)

28. Schwaninger, M.S., Ulli-Beer, S., Kaufmann-Hayoz, R.: Policy Analysis and Design in Local Public Management - A System Dynamics Approach. In: Handbook of Transdisciplinary Research, pp. 205-221. Springer, Heidelberg (2007)

29. Zamanipour, M.: A System Dynamics Model for Analyzing the Effects of Government Policies: A Case Study of Iran's Cell Phone Market. In: Proceedings of the 27th International Conference of the System Dynamics Society, Albuquerque, New Mexico, USA (2009)

30. Teekasap, P.: Cluster Formation and Government Policy: System Dynamics Approach. In: Proceedings of the 27th International Conference of the System Dynamics Society, Albuquerque, New Mexico, USA (2009) 